\title{
The effect of activated carbon and silicon oxycarbide as anode materials on lithium-ion battery
}

\author{
Bambang Priyono ${ }^{1}$, Natasha Chandri Egieara ${ }^{1}$, Anne Zulfia Syahrial ${ }^{1}$, Chairul Hudaya ${ }^{2},{\text { Achmad } \text { Subhan }^{3} \text {, and Heri Jodi }}^{4}$ \\ ${ }^{1}$ Department of Metallurgical and Materials Engineering, Universitas Indonesia, Depok, 16424, Indonesia \\ ${ }^{2}$ Departement of Electrical Engineering, Universitas Indonesia, Depok, 16424, Indonesia \\ ${ }^{3}$ Research Centre for Physics - LIPI, PUSPITEK, Tangerang, Banten, 15310, Indonesia \\ ${ }^{4}$ Centre for Science and Technology of Advanced Materials, National Nuclear Energy Agency - BATAN, PUSPITEK, \\ Tangerang, Banten, 15310, Indonesia
}

\begin{abstract}
SiOC@C is a lithium-ion battery (LIB) anode candidate that is expected to suppress the high volume expansion of $\mathrm{Si}$ by the presence of activated carbon as a buffer layer. Silicon oxycarbide ( $\mathrm{SiOC}$ ) was obtained from phenyl-rich silicone oil through pyrolysis at $900^{\circ} \mathrm{C}$ with flowing $\mathrm{Ar}$ gas. The variation of samples used were 4 and $10 \mathrm{wt} \% \mathrm{SiOC}$ and a pure carbon sample was also prepared for comparison. SEM images show a porous microstructure with a few chunks of agglomerate present. According to Brunner-Emmet-Teller (BET) test, the largest surface area of $542.738 \mathrm{~m}^{2} / \mathrm{g}$ was obtained at $10 \mathrm{wt} . \% \mathrm{SiOC}$. Based on the performance test result, the highest discharge capacity of $223.3 \mathrm{mAh} / \mathrm{g}$ was obtained at the mentioned prime condition.
\end{abstract}

\section{Introduction}

The development of batteries has progressed significantly over the years due to its diverse and massive applications in various fields and technologies. As a result, there is a high market interest for such high performance and safe technology that has now turned into the standard power source. The demand continues to grow as Li-ion batteries show enhanced battery performance thus making it even more applicable for a broad range of applications, including consumer electronics, e.g., cell phones, laptop computers. Moreover, Li-ion batteries (LIBs) contribute in providing a storage device for transportation, communications, and renewable sectors due to its desirable high electric voltage and energy density. As time and technology progresses, Li-ion batteries require some alterations in order to stay relevant [1].

There are many potential electrode materials, however, their usage is usually limited by issues such as low thermal stability, mechanical brittleness, and high volume expansion [2]. Numerous methods have been proposed to tackle these obstacles; in this matter, it involves using the mixture of silicon oxycarbide and activated carbon as anode materials. Si-based material is being regarded as a viable option to replace graphite in high-density LIBs due to its high theoretical capacity of $4200 \mathrm{~mA} \mathrm{~h} \cdot \mathrm{g}^{-1}$, environmentally friendly character, and natural abundance of silicone [3]. However, $\mathrm{Si}$ is known to have low electric conductivity and huge volume variation of over $300 \%$ during lithiation and delithiation, thus impeding the success of Si-based anodes

\footnotetext{
Corresponding author: bambang.priyono@ui.ac.id
}

implementation in practical applications. To overcome this issue, introducing a carbonaceous material, e.g., activated carbon, is expected to improve the $\mathrm{Si}$-based anode performance by alleviating the volume change and mechanical stress, along with increasing its electronic properties [3].

\section{Experimental Procedure}

The process of creating SiOC@C as an active material involves 2 steps: the synthesis of activated carbon and silicon oxycarbide. This experiment used three variations of \%wt SiOC (i.e., 4 wt.\% and $10 \mathrm{wt} . \%$ SiOC) as the parameters in determining the optimum combination for the fabrication of anode material. Both processes employed pyrolysis method to obtain the components.

\subsection{Synthesis of activated carbon}

First of all, the chunks of commercial carbon are milled into powder form and must be activated through a series of steps [4] . The first heating is conducted at $500^{\circ} \mathrm{C}$ for 2 hours using a furnace and the heated carbon powder is poured into a mixture of $\mathrm{NaOH}$ pellets and $10 \mathrm{ml}$ of distilled water. This mixture is stirred for 2 hours with the help of a magnetic stirrer to ensure homogeneity and dried at $130^{\circ} \mathrm{C}$ for 4 hours. After that, the second heating proceeds under $100 \mathrm{~cm}^{3} \mathrm{~min}^{-1}$ of nitrogen gas flow at $700^{\circ} \mathrm{C}$ for 1.5 hours. The carbon is then rinsed by $0.1 \mathrm{M}$ $\mathrm{HCl}$, followed by hot distilled water until the $\mathrm{pH}$ reached 6.5 and filtered it once more. In order to obtain a thoroughly dry sample, the activated carbon is dried at 


\section{$110^{\circ} \mathrm{C}$ for 24 hours.}

\subsection{Synthesis of SiOC@C}

After that, silicone oil has to morph into SiOC before it is used in battery fabrication. In this process, the silicone oil used was obtained from Sigma Aldrich (SIG). The synthesis of SiOC involves mixing the silicone oil and activated carbon altogether and transferring them into a combustion boat for heating. The heating is conducted under a flow of argon gas at a temperature rate of $300^{\circ} \mathrm{C}$ to $900^{\circ} \mathrm{C}$, in which it is maintained for 1 hour. This process produces a black powder with a hint of lustrous particles [5].

\subsection{Battery fabrication}

A slurry of $8: 1: 1$ ratio consisting of active material, acetylene black as a conductive agent, and PVDF as a binder, along with 5 grams of DMAC as a solvent is used. The active material constitutes of SiOC@C powder in various amount of wt.\% SiOC. In order to ensure the homogeneity of the slurry, the mixture is stirred using a magnetic stirrer at $80^{\circ} \mathrm{C}$. The slurry is then coated onto $\mathrm{Cu}$ foil using doctor blade and left to dry for 1 hour in the oven. The anode material is ready to be cut into circular working electrodes $(16 \mathrm{~mm}$ in diameter) and assembled into coin-type cells. $\mathrm{LiPF}_{6}$ and polypropylene are used as the electrolyte and separator respectively.

\subsection{Characterisation tests}

Once the anode material and coin battery are ready, they are then characterized. The characterization tests used to analyze the anode materials are XRD, SEM-EDS, and BET. On the other hand, the battery's performance is assessed by cyclic voltammetry (CV) test, chargedischarge testing, and electrochemical impedance spectroscopy (EIS).

\section{Result and discussion}

The first characterization test executed in this experiment was BET test. This test was conducted using Quantachrome NovaWin with adsorption of nitrogen gas at $77.3 \mathrm{~K}$ on pre and post-activated carbon, and all variations of $\%$ wt SiOC. The surface area of preactivated carbon is $224.847 \mathrm{~m}^{2} / \mathrm{g}$, whilst the postactivated carbon is $490.007 \mathrm{~m}^{2} / \mathrm{g}$. This shows an increase of surface area by two folds, which supports the claim that activation process of carbon increases surface area by the formation and merge of pores within the structure . On the other hand, the highest surface area amongst the samples containing various amount $\mathrm{SiOC}$ is observed in $10 \%$ wt $\mathrm{SiOC}$ at $542.738 \mathrm{~m}^{2} \mathrm{~g}$.

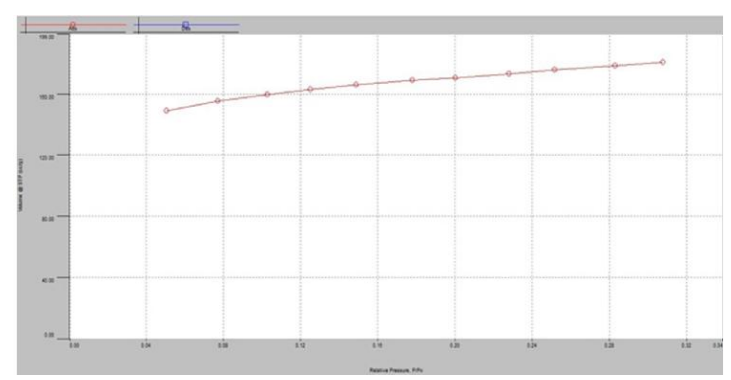

(a)

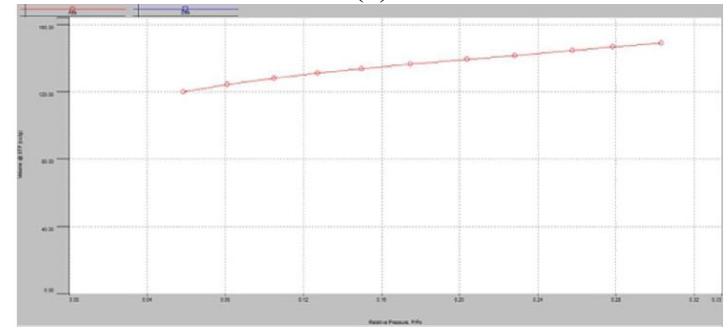

(b)

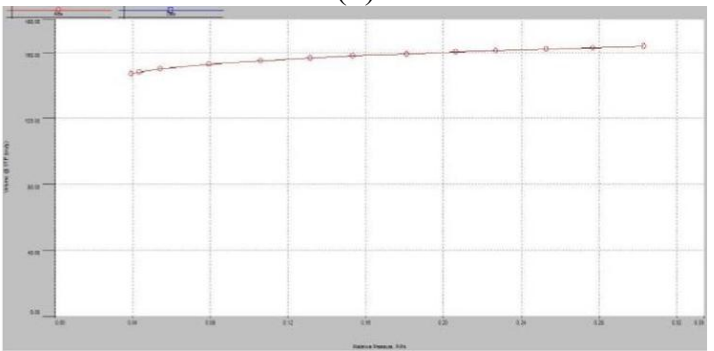

(c)

Fig. 1. BET result of (a) 4wt.\% SiOC, (b) 10wt.\% SiOC, and pure activated carbon sample.

In order to observe the morphology of the samples, Scanning Electron Micrograph - Energy Dispersive Spectroscopy was conducted. The SEM result of activated carbon shows the presence of a few chunks of agglomerates and cloud-like porous structure as the product of activation. Based on the elemental mapping result, the agglomerates are proven to be carbon that had not been reduced in size due to insufficient milling period.

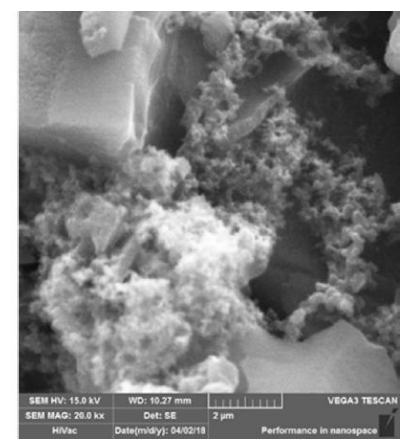

Fig. 2. SEM result of activated carbon at $20,000 \mathrm{X}$ magnification.

A similar morphology of porous structure is observed in 4 and $10 w t \%$ SiOC SEM results. This shows that the activation process of carbon was successful, which 
therefore contributes in shorter transfer range of lithium ion, thus faster charge-discharge time .
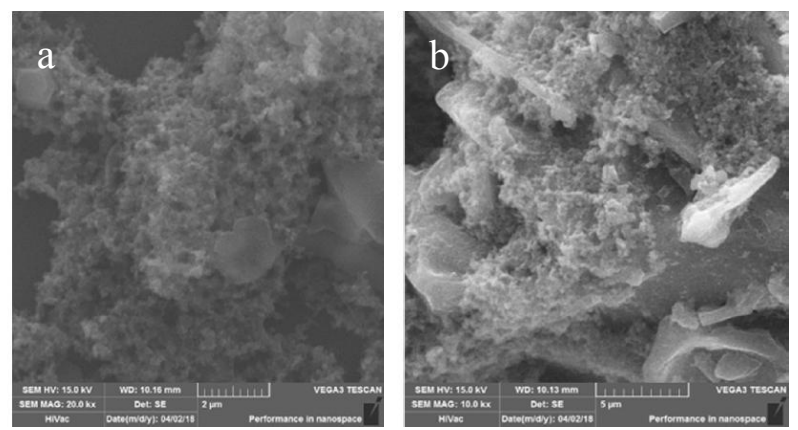

Fig. 3. SEM results of (a) $4 \%$ wt. SiOC and (b) $10 \%$ wt. $\mathrm{SiOC}$ at 20,000X magnification.

Another characterization test performed was X-ray Diffraction test. This test yields information regarding the phases formed within the sample in the form of peaks. According to the previous research, SiOC did not undergo any phase transformation which means that it remained amorphous through lithiation and delithiation [5]. The peak at $2 \theta=21^{\circ}$ shows the presence of graphene and the presence of $\mathrm{Si}$ is marked at $2 \theta=44.5^{\circ}$, $55.5^{\circ}, 64.2^{\circ}$, and $74^{\circ}$.

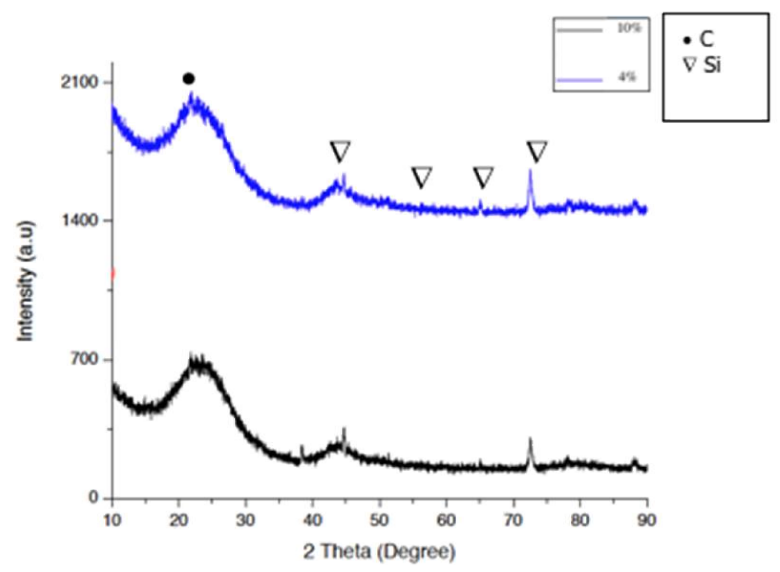

Fig. 4. XRD results of 4 and 10wt. $\% \mathrm{SiOC}$.

Lastly, the working potential of each sample was measured by cyclic voltammetry (CV) test. The Si anodic peak appears more visibly as the $\mathrm{Si}$ content increases, in which it is most prominent in $\mathrm{SiOC} 10 \%$ at $0.668 \mathrm{~V}$. On the other hand, $4 \%$ wt $\mathrm{SiOC}$ shows a gentler peak at $1.174 \mathrm{~V}$. The highest specific capacity of 223.3 $\mathrm{mAh} / \mathrm{g}$ is obtained at $10 \mathrm{wt} . \% \mathrm{SiOC}$. The average capacity could not be calculated as the cathodic peaks do not appear in this graph. This is phenomenon is attributed to the formation of solid electrolyte interface (SEI) layer created by the decomposition of eletcrolytes and irreversible $\mathrm{Li}^{+}$trapping [6].
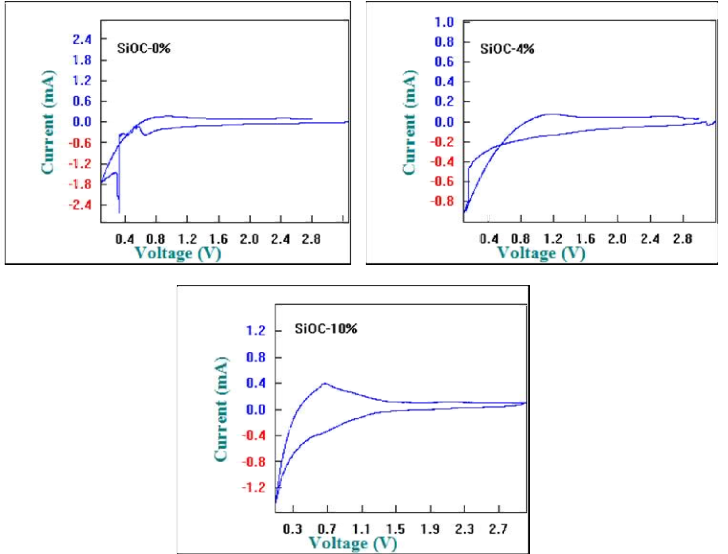

Fig. 5. CV results of 4 and 10wt.\% SiOC sample and pure carbon sample.

The charge-discharge result shows that the discharge rate was given from current rate $0.2 \mathrm{C}$ to $15 \mathrm{C}$ and it displays a trend where the capacity decreases at higher $\mathrm{C}$ rate. In this experiment, the same trend is observed in all samples containing SiOC and a higher specific discharge capacity is observed as the SiOC content increases [5].

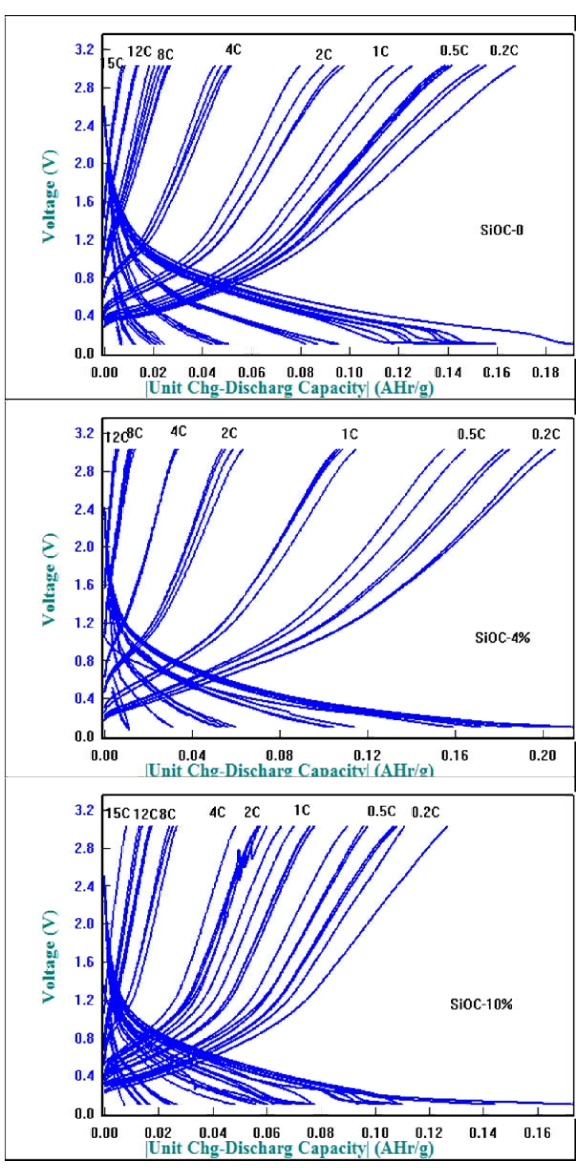

Fig. 6. Charge-discharge results of pure carbon sample and 4 and $10 \mathrm{wt} . \%$ SiOC sample.

However, at lower $\mathrm{C}$ rate of $7 \% \mathrm{wt}$, an irregular pattern is observed as there is a quite significant rise in 
specific discharge capacity $(247 \mathrm{mAH} / \mathrm{g}$ ), in which it was originally expected to be lower than that of $4 \% \mathrm{wt}$ SiOC $(213.1 \mathrm{mAh} / \mathrm{g})$. Moreover, it is observed that the average coulombic efficiency at $10 \%$ wt $\mathrm{SiOC}$ is high, thus indicating small loss of electric energy during charging.

According to EIS result shown in Table 1, the lowest

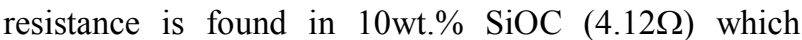
means that it exhibits a good conductivity. This supports the literature in which it states that the value of resistance is inversely proportional to the conductivity value.

Table 1. Rct values of all samples.

\begin{tabular}{cc}
\hline Sample & Ret $(\Omega)$ \\
\hline Pure carbon & 92.23 \\
4wt.\% SiOC & 94.30 \\
10wt.\% SiOC & 84.86 \\
\hline
\end{tabular}

\section{Conclusion}

The synthesis of activated carbon and SiOC employs pyrolytic method. SiOC exists in an amorphous form thus it remains undetected in XRD test. The highest specific surface area, discharge capacity, and conductivity is obtained in $10 \% \mathrm{wt}$ SiOC sample. Although there are observable drawbacks of using the combination of SiOC@C as anode material, this experiment leaves room for improvement for further development of the material.

The authors would like to thank the Direktorat Riset dan Pengabdian Masyarakat Universitas Indonesia (DRPM-UI) for the financial support under the grant of Hibah PITTA with contract number: PITTA/561/FT/2018.

\section{References}

[1] B. Priyono, A. Z. Syahrial, A. H. Yuwono, E. Kartini, M. Marfelly, and W. M. F. Rahmatulloh, "Synthesis of Lithium Titanate (Li4Ti5O12) through Hydrothermal Process by using Lithium Hydroxide (LiOH) and Titanium Dioxide (TiO2) Xerogel," International Journal of Technology, vol. 6, no. 4, pp. 555-564, Oct. 2015.

[2] N. Nitta, F. Wu, J. T. Lee, and G. Yushin, "Liion battery materials: Present and Future," Materials Today, vol. 18, no. 5, pp. 252-264, 2015.

[3] X. Xin, X. Yao, Y. Zhang, Z. Liu, and X. Xu, "Si/C nanocomposite anode materials by freezedrying with enhanced electrochemical performance in lithium-ion batteries," Journal of Solid State Electrochemistry, vol. 16, no. 8, pp. 2733-2738, 2012.

[4] A. L. Cazetta, A. M. M. Vargas, E. M. Nogami, M. H. Kunita, M. R. Guilherme, A. C. Martins, T. L. Silva, J. C. G. Moraes, and V. C. Almeida, " $\mathrm{NaOH}$-activated carbon of high surface area produced from coconut shell: Kinetics and equilibrium studies from the methylene blue adsorption," Chemical Engineering Journal, vol. 174, pp. 117-125, 2011.

[5] M. Halim, C. Hudaya, A.-Y. Kim, and J. K. Lee, "Phenyl-rich silicone oil as a precursor for $\mathrm{SiOC}$ anode materials for long-cycle and high-rate lithium ion batteries," Journal of Materials Chemistry A, vol. 4, no. January, pp. 2651-2656, 2016.

[6] D. Ma, Z. Cao, and A. Hu, "Si-Based Anode Materials for Li-ion Batteries: A Mini Review," Nano-Micro Letters, vol. 6, no. 4, 2014. 